\title{
CHEMICAL SHIFT OF X-RAY $K$-ABSORPTION EDGE OF Ni IN SOME OF ITS COMPOUNDS AND ITS CORRELATION WITH PARTIAL CHARGE
}

\author{
V.K. Singh, A.R. Chetal \\ Department of Applied Physics, Indian School of Mines, Dhanbad, India \\ AND P.R. SARODE \\ Department of Physics, Goa University, Goa, India \\ (Received September 2, 1994; revised version December 20, 1994) \\ $\mathrm{X}$-ray absorption $\mathrm{Ni} K$-edge spectra are recorded for the following sys- \\ tems: $\mathrm{Ni}$ metal, $\mathrm{Ni}\left(\mathrm{NO}_{3}\right)_{2} \cdot 6 \mathrm{H}_{2} \mathrm{O}, \mathrm{Ni}_{3}\left(\mathrm{PO}_{4}\right)_{2} \cdot 6 \mathrm{H}_{2} \mathrm{O}, \mathrm{NiSO}_{4} \cdot 6 \mathrm{H}_{2} \mathrm{O}, \mathrm{NiCO}_{3}$, \\ $\mathrm{NiO}$ and $\mathrm{La}_{2} \mathrm{NiO}_{4}$ using a Cauchois-type bent crystal spectrograph. The \\ chemical shift of these systems is correlated with the partial charge deter- \\ mined using Sanderson's method. On the basis of regression analysis a rela- \\ tion $\Delta E=A_{0}+A_{1} q+A_{2} q^{2}+A_{3} q^{3}+A_{4} q^{4}$ between the chemical shift, $\Delta E$, \\ and the partial charge, $q$, has been suggested. The discrepancy in the shift \\ of $\mathrm{NiO}$ and $\mathrm{La}_{2} \mathrm{NiO}_{4}$ has also been discussed.
}

PACS numbers: 78.70.Dm

\section{Introduction}

The formation of a compound or complex causes a change in the chemical environment around the central ion and due to this modification the binding energy of the ion changes as well. The change in binding energy is reflected in the position of the absorption edge of a compound or complex. The chemical shift of a compound or complex is defined as a difference of the energy of the absorption edge of the metal in a compound or complex and in a pure metallic state, i.e. the chemical shift, $\Delta E$, (in $\mathrm{eV}$ ) is given by

$$
\Delta E=E_{\text {Compound }}-E_{\text {Metal }} \text {, }
$$

where $E_{\text {Compound }}=$ energy (in $\mathrm{eV}$ ) of the absorption edge in a compound and $E_{\text {Metal }}=$ energy of the absorption edge in a pure metal. The chemical shift depends upon various factors [1-6] such as effective charge, valency, nature of ligands, coordination number, etc. 
In this paper, we have investigated the systems $\mathrm{Ni}\left(\mathrm{NO}_{3}\right)_{2} \cdot 6 \mathrm{H}_{2} \mathrm{O}$, $\mathrm{Ni}_{3}\left(\mathrm{PO}_{4}\right)_{2} \cdot 6 \mathrm{H}_{2} \mathrm{O}, \mathrm{NiSO}_{4} \cdot 6 \mathrm{H}_{2} \mathrm{O}, \mathrm{NiCO}_{3}, \mathrm{NiO}$ and $\mathrm{La}_{2} \mathrm{NiO}_{4}$ which have the same oxidation state, coordination number and the nearest neighbour as oxygen. We correlated the chemical shift with a charge on the absorbing ion and suggested a relation between the chemical shift and partial charge based on the method of the least square regression analysis. The experimental details are described elsewhere [7].

\section{Results and discussion}

The increase in valency enhances the chemical shift. The valence dependence of the shift has been used by various workers [8-10] to determine the valency of the absorbing ion in compounds and complexes. However, it has been observed that the systems having the same valency show a different chemical shift. This fact was explained by Sapre and Mande [9] on the basis of covalency. The covalency suppresses the shift while the ionicity enhances it. It was shown by Chetal [11] that the chemical shift in the octahedral systems is larger than in the tetrahedral systems. The systems under study are divalent and are having six coordination numbers. Further, their nearest neighbours are also the same, i.e. oxygen. Thus valency, coordination number and nearest neighbour atoms are the same in the chemical shift observed by us.

The partial charge on the system under study has been calculated using the method suggested by Sanderson [12]. According to Sanderson, the effective charges on atoms less than the charge of an electron are called partial charges. The partial charge on a combined atom of a compound is then the ratio of the electronegativity change undergone by the atom in the process of forming the compound to the electronegativity change that it would have undergone in acquiring unit charge. It is given by

$$
q=\frac{S_{M}-S_{E}}{\Delta S_{E \rightarrow E_{ \pm}}}=\frac{S_{M}-S_{E}}{2.08 \sqrt{S_{E}}} .
$$

IIere, $S_{E}$ and $S_{M}$ are the electronegativities of the element $E$ and molecule (compound), respectively. $\Delta S_{E \rightarrow E_{ \pm}}$is the electronegativity change per unit charge and Sanderson showed that this equals $2.08 \sqrt{S_{E}}$. The value of the partial charge, ionicity and chemical shift of $\mathrm{Ni} K$-edge in the systems under study are given in Table I. A large number of measurements were made on each sample. The chemical shift shown in Table I is actually the average of all these readings. The energy of $\mathrm{Ni}$ $K$-edge in Ni metal has been estimated as $8331.62 \mathrm{eV}$ which agrees with the value 8331.65 given by Bearden [13].

Several workers [14-17] have correlated the shift, $\Delta E$, with the charge, $q$, with the equation of a type

$$
\Delta E=\sum_{i=1}^{n} A_{i} q^{i},
$$

where $A_{1}, A_{2}, A_{3}, A_{4}, \ldots$ are constants which arise due to the hole-site effects, the Madelung potential term, the Watson-Bannet-Davenport type energy term 
TABLE I

Chemical shift of the $\mathrm{Ni} K$-edge in copper systems.

\begin{tabular}{c|l|c|c|c|c}
\hline \hline $\begin{array}{c}\text { S. } \\
\text { No. }\end{array}$ & $\begin{array}{l}\text { Name of } \\
\text { absorber }\end{array}$ & $\begin{array}{c}\text { Chemical } \\
\text { shift, } \\
\Delta E(\mathrm{eV})\end{array}$ & $\begin{array}{c}\text { Partial } \\
\text { charge, } q \\
\text { (electrons } \\
\text { per atom) }\end{array}$ & Ionicity & $\begin{array}{c}\text { Electrone- } \\
\text { gativity }\end{array}$ \\
\hline 1. & $\mathrm{Ni}_{\left(\mathrm{NO}_{3}\right)_{2} \cdot 6 \mathrm{H}_{2} \mathrm{O}}$ & 9.18 & 0.69 & 0.81 & 4.18 \\
2. & $\mathrm{Ni}_{3}\left(\mathrm{PO}_{4}\right)_{2} \cdot 6 \mathrm{H}_{2} \mathrm{O}$ & 8.00 & 0.62 & 0.79 & 3.97 \\
3. & $\mathrm{NiSO}_{4} \cdot 6 \mathrm{H}_{2} \mathrm{O}$ & 7.98 & 0.60 & 0.81 & 3.91 \\
4. & $\mathrm{NiCO}_{3}$ & 6.98 & 0.58 & 0.80 & 3.85 \\
5. & $\mathrm{La}_{2} \mathrm{NiO}_{4}$ & 6.30 & 0.45 & 0.69 & 3.31 \\
6. & $\mathrm{NiO}$ & 6.70 & 0.40 & 0.84 & 3.46
\end{tabular}

TABLE II Correlation coefficient $\gamma$, standard error $S$ and LSF (least square fit) parameters for $\Delta E=\sum_{i=1}^{n} A_{i} q^{i}$.

\begin{tabular}{|c|c|c|c|c|}
\hline $\begin{array}{l}\text { S. } \\
\text { No. }\end{array}$ & Equation & $\begin{array}{c}\mathrm{LSF} \\
\text { parameters }\end{array}$ & $\begin{array}{l}\text { Correlation } \\
\text { coefficient, } \gamma\end{array}$ & $\begin{array}{l}\text { Standard } \\
\text { error, } S\end{array}$ \\
\hline 1. & $\Delta E=A_{1} q$ & $A_{1}=0.1336120 \times 10^{2}$ & 0.888 & 0.658 \\
\hline 2. & $\Delta E=A_{1} q+A_{2} q^{2}$ & $\begin{array}{l}A_{1}=0.1830164 \times 10^{2} \\
A_{2}=-0.8368884 \times 10^{1}\end{array}$ & 0.858 & 0.508 \\
\hline 3. & $\begin{array}{l}\Delta E=A_{1} q+A_{2} q^{2} \\
\quad+A_{3} q^{3}\end{array}$ & $\begin{array}{l}A_{1}=0.2256083 \times 10^{3} \\
A_{2}=-0.1116534 \times 10^{3} \\
A_{3}=0.9376754 \times 10^{2}\end{array}$ & 0.960 & 0.272 \\
\hline 4. & $\begin{array}{c}\Delta E=A_{1} q+A_{2} q^{2} \\
\quad+A_{3} q^{3}+A_{4} q^{4}\end{array}$ & $\begin{array}{l}A_{1}=0.2256083 \times 10^{3} \\
A_{2}=-0.1111353 \times 10^{4} \\
A_{3}=0.1904585 \times 10^{4} \\
A_{4}=-0.1072371 \times 10^{4}\end{array}$ & 0.977 & 0.209 \\
\hline 5. & $\begin{array}{l}\Delta E=A_{1} q+A_{2} q^{2} \\
\quad+A_{3} q^{3}+A_{4} q^{4} \\
+A_{5} q^{5}\end{array}$ & $\begin{array}{l}A_{1}=0.9783173 \times 10^{2} \\
A_{2}=-0.2556764 \times 10^{3} \\
A_{3}=-0.1869712 \times 10^{4} \\
A_{4}=0.1142846 \times 10^{4} \\
A_{5}=-0.8581307 \times 10^{3}\end{array}$ & 0.983 & 0.179 \\
\hline
\end{tabular}

corresponding to the overlap and hybridization effects and the valence $d$-orbital effects, and $\mathrm{Ma}$ and Brueckner type correlation energy, respectively.

We tried to correlate our results with one of the above equations. However, it was found that the correlation coefficient and standard error did not show any 
trend as it is evident from Table II and hence we correlated our results with the equation of the following type:

$$
\Delta E=\sum_{i=0}^{n} A_{i} q^{i}
$$

The values of the least square fit parameters $A_{0}, A_{1}, A_{2}, A_{3}, \ldots$, the correlation coefficient, $\gamma$, and the standard error, $S$, for each equation are given in Table III. From this table it is clear that the value of the maximum correlation coefficient and minimum standard error are given by the following equation:

$$
\Delta E=A_{0}+A_{1} q^{1}+A_{2} q^{2}+A_{3} q^{3}+A_{4} q^{4} .
$$

TABLE III Correlation coefficient $\gamma$, standard error $S$ and LSF (least square fit) parameters

\begin{tabular}{|c|c|c|c|c|}
\hline $\begin{array}{l}\text { S. } \\
\text { No. }\end{array}$ & Equation & $\begin{array}{c}\text { LSF } \\
\text { parameters }\end{array}$ & $\begin{array}{l}\text { Correlation } \\
\text { coefficient, } \gamma\end{array}$ & $\begin{array}{c}\text { Standard } \\
\text { error, } S\end{array}$ \\
\hline 1. & $\Delta E=A_{0}+A_{1} q$ & $\begin{array}{l}A_{0}=0.4321588 \times 10^{0} \\
A_{1}=0.1260925 \times 10^{2}\end{array}$ & 0.978 & 0.582 \\
\hline 2. & $\begin{array}{l}\Delta E=A_{0}+A_{1} q \\
\quad+A_{2} q^{2}\end{array}$ & $\begin{array}{l}A_{0}=0.7540983 \times 10^{-1} \\
A_{1}=0.1801435 \times 10^{2} \\
A_{2}=-0.8104504 \times 10^{1}\end{array}$ & 0.986 & 0.470 \\
\hline 3. & $\begin{array}{l}\Delta E=A_{0}+A_{1} q \\
\quad+A_{2} q^{2}+A_{3} q^{3}\end{array}$ & $\begin{array}{l}A_{0}=0.4180094 \times 10^{-2} \\
A_{1}=0.4579739 \times 10^{2} \\
A_{2}=-0.1114359 \times 10^{3} \\
A_{3}=0.9358404 \times 10^{2}\end{array}$ & 0.996 & 0.251 \\
\hline 4. & $\begin{array}{l}\Delta E=A_{0}+A_{1} q \\
\quad+A_{2} q^{2}+A_{3} q^{3} \\
\quad+A_{4} q^{4}\end{array}$ & $\begin{array}{l}A_{0}=0.7983616 \times 10^{-3} \\
A_{1}=0.1515731 \times 10^{3} \\
A_{2}=-0.7002025 \times 10^{3} \\
A_{3}=0.1160969 \times 10^{4} \\
A_{4}=-0.6326573 \times 10^{3}\end{array}$ & 0.998 & 0.172 \\
\hline 5. & $\begin{array}{l}\Delta E=A_{0}+A_{1} q \\
\quad+A_{2} q^{2}+A_{3} q^{3} \\
+A_{4} q^{4}+A_{5} q^{5}\end{array}$ & $\begin{array}{l}A_{0}=0.3025365 \times 10^{-2} \\
A_{1}=0.3750117 \times 10^{3} \\
A_{2}=-0.2458153 \times 10^{4} \\
A_{3}=0.6265540 \times 10^{4} \\
A_{4}=-0.7113303 \times 10^{4} \\
A_{5}=0.3036281 \times 10^{4}\end{array}$ & 0.997 & 0.199 \\
\hline
\end{tabular}
for $\Delta E=\sum_{i=0}^{n} A_{i} q^{i}$.

Therefore, Eq. (5) will be the most suitable relation between the chemical shift, $\Delta E$, and the partial charge, $q$, for the systems under study. The data points 
of the chemical shift versus partial charge are given in Fig. 1 along with the points for the chemical shift obtained using Eq. (5). It can be seen from the figure that theoretical and experimental data match very well. This again suggests the suitability of Eq. (5) as the most suitable relation between the chemical shift, $\Delta E$, and the partial charge, $q$. The correlation coefficient of the best fit relation does not equal 1. This is due to the various errors such as an error of omitted variables, error in the mathematical form of the model, error of measurement of the dependent variable, etc. In order to take into account this fact, we have performed the $F$-test, which tests the significance of the regression done by us. The value of $F^{*}$ of each equation is given in Table IV. The $F^{*}$ value is the maximum of Eq. (5), which

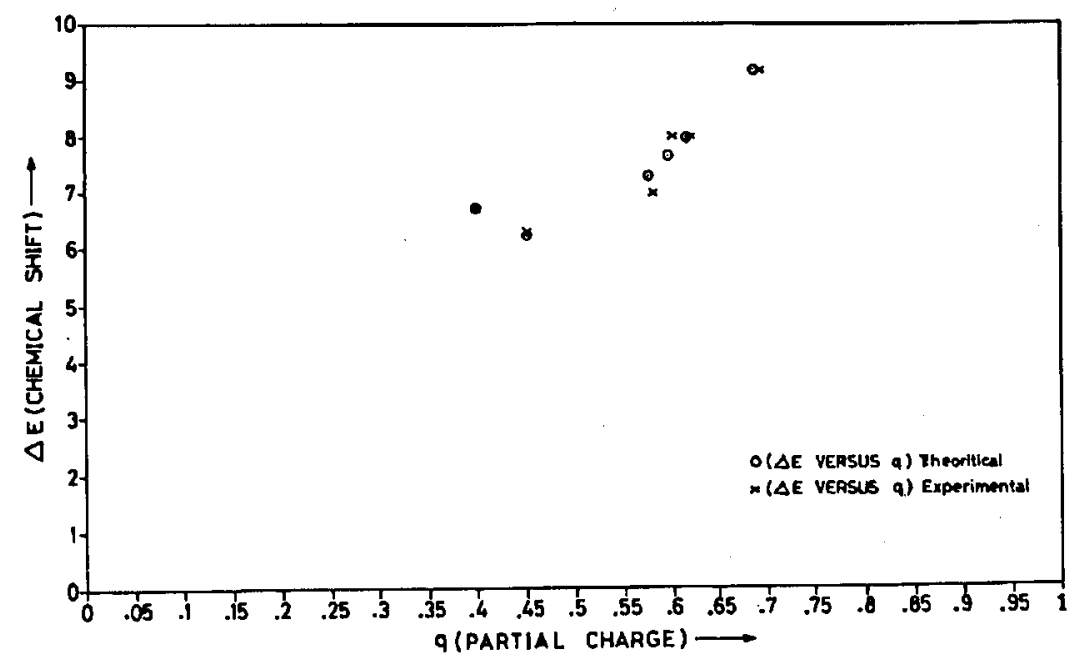

Fig. 1. Chemical shift (in $\mathrm{eV}$ ) versus partial charge.

TABLE IV

$F^{*}$ values for different equations of type $\Delta E=\sum_{i=1}^{n} A_{i} q^{i}$.

\begin{tabular}{c|c|c|c|c|c}
\hline \hline $\begin{array}{c}\text { S. } \\
\text { No. }\end{array}$ & Equations & $\begin{array}{c}\text { Explained } \\
\text { variation }\end{array}$ & $\begin{array}{c}\text { Unexpl. } \\
\text { variation }\end{array}$ & $\begin{array}{c}\text { Total varia- } \\
\text { tion in } \Delta E\end{array}$ & $F^{*}$ \\
\hline 1 & $\Delta E=A_{0}+A_{1} q$ & 51.80 & 2.36 & 54.16 & 109.08 \\
\hline 2 & $\Delta E=A_{0}+A_{1} q+A_{2} q^{2}$ & 52.62 & 1.54 & 54.16 & 170.33 \\
\hline 3 & $\begin{array}{c}\Delta E=A_{0}+A_{1} q+A_{2} q^{2} \\
+A_{3} q^{3}\end{array}$ & 53.72 & 0.44 & 54.16 & 607.26 \\
\hline 4 & $\begin{array}{c}\Delta E=A_{0}+A_{1} q+A_{2} q^{2} \\
+A_{3} q^{3}+A_{4} q^{4}\end{array}$ & 53.90 & 0.21 & 54.16 & 1300.24 \\
\hline 5 & $\begin{array}{c}\Delta E=A_{0}+A_{1} q+A_{2} q^{2} \\
+A_{3} q^{3}+A_{4} q^{4}+A_{5} q^{5}\end{array}$ & 53.84 & 0.28 & 54.16 & 966.10 \\
& & & &
\end{tabular}


also confirms that the equation chosen by us is the best fit. It is clear from Eq. (5) that if $q$ equals zero, $\Delta E=A_{0}=0.0008$, which means that not only the partial charge but also the chemical shift is also governed by some other factors such as the ionicity, crystal structure, etc. It can be seen from Table I that the chemical shift of $\mathrm{NiO}$ is greater than $\mathrm{La}_{2} \mathrm{NiO}_{4}$, although the partial charge on the absorbing ion $\mathrm{Ni}$ in $\mathrm{NiO}$ is smaller than $\mathrm{La}_{2} \mathrm{NiO}_{4}$. This discrepancy may be due to the fact that the ionicity in case of $\mathrm{NiO}$ is greater than the ionicity of $\mathrm{La}_{2} \mathrm{NiO}_{4}$.

\section{References}

[1] V. Kunzl, Collect Trav. Chim. Tchecoslovaque 4, 213 (1932).

[2] A.R. Chetal, P.R. Sarode, J. Phys. F 5, L217 (1975); 7(4), 745 (1977).

[3] M.M. Ballal, C. Mande, J. Phys. Chem. Solids 38, 843 (1977).

[4] P.A. Lee, F. Boehm, P. Vogel, Phys. Lett. A 63, 251 (1977).

[5] K. Hemahandran, A.R. Chetal, Phys. Status Solidi B 136, 181 (1986); 138, 229 (1986).

[6] R. Ubgade, P.R. Sarode, Phys. Status Solidi B 99, 295 (1987).

[7] V.K. Singh, A.R. Chetal, $X$-ray Spectrometry, Vol. 22, 1993, p. 86.

[8] B.K. Agarwal, L.P. Verma, J. Phys. C 3, 535 (1970).

[9] V.B. Sapre, C. Mande, J. Phys. C 5, 793 (1972).

[10] A. Miller, Phys. Chem. Solids 29, 633 (1963).

[11] A.R. Chetal, Ph.D. Thesis, Poona Univ., Poona 1965.

[12] R.T. Sanderson, Chemical Bonds and Bond Energy, Academic Press, New York 1976, p. 77.

[13] J.A. Bearden, Nat. Stand. Ref. Data Ser. NBS 14, Atomic and Molecular Properties, U.S. Government Printing Office, Washington, New York 1967.

[14] V.K. Kondawar, C. Mande, J. Phys. C 9, 1351 (1976).

[15] P.R. Sarode, S. Ramasesha, W.H. Madhusudan, C.N.R. Rao, J. Phys. C, Solid State Phys. 12, 2439 (1979).

[16] S.K. Pandey, A.R. Chetal, Phys. Status Solidi B 165, 295 (1991).

[17] S.K. Pandey, A.R. Chetal, J. Phys. Soc. Jpn. 59, 1848 (1990). 